\title{
A Study on the Development of the Storytelling Contents based on the Exile Life and Literature Works of Man-Jung Kim
}

\author{
Jung-Gon Lee1), Duk-Hwan Kim²), Dae-Yul Jeong3)
}

\begin{abstract}
This paper proposes how to develop storytelling contents for foster local culture industry based on the lifestyle and literature works of Man-Jung Kim, a great scholar in the late Joseon dynasty. He wrote various literary works such as classic novels, poetries, proses, and criticisms during his exile life. Storytelling content based on his work will play an important role in globalizing Korean contents. The development method of storytelling contents uses the basic elements: 'text + narration + champ' based on the champ theory. We will look at similar storytelling content development cases based on the exile literature in Korea and benchmark them to develop Kim's storytelling content development plans. Twelve experts participate to brainstorm for developing various new ideas of storytelling contents. It is important to approach Kim's work from a comprehensive and integrated perspective in order to develop valuable storytelling contents. Concludingly, to build local cultural assets, it is important to focus not only on the core values of Kim's works, but also in building a collaborative system among local governments, storytellers, cultural artists, tourists, and citizens.
\end{abstract}

Keywords: Man-Jung Kim, Exile Literature, Storytelling Contents, Champ Theory, Cultural Contents, Local Culture Assets

\section{Introduction}

Man-Jung Kim (1637 1692), pan-name Seopo, was a great writer and classical scholar in the Joseon Dynasty. All his life was based on loyalty to the state and filial piety to his parents. He was sentenced to live in exile by his lord, King Sukjong, in Seoncheon, Pyeonganbuk-do (1687) and Namhae, Gyeongsnam-do (1689) due to his political moves called strife between the parties. Namhae-gun (here after Namhae) is a small local government located south of the

Received(November 14, 2019), Review Result(1st: December 18, 2019, 2nd: January 31, 2020), Accepted(April 25, 2020)

1) (Ph. D. Course) 52828 Dept. Cultural Convergence, Gyeongsang National University, Jinju, Gyeongsangnam-do, Korea

email: baekunsan@hanmail.net

2) (Professor) 52828 Dept. of Chinese Language and Literature, Gyeongsang National University, Jinju, Gyeongsangnam-do, Korea

email: mugam20@hanmail.net

3) (Professor, Corresponding Author) 52828 Dept. of Management Information Systems, Research Fellow of BERI, Gyeongsang National University, Jinju, Gyeongsangnam-do, Korea

email: dyjeong@gnu.ac.kr 
A Study on the Development of the Storytelling Contents based on the Exile Life and Literature Works of Man-Jung Kim

Korean peninsula. His exile to Namhae was his peak of literacy writing. He stayed for three years and one month until his death in Namhae. In order to honor his works and other exile literature works, Namhae local government built the 'Namhae Exile Literature Museum', and designated Nodo Island as the 'Island of Literature'. Kim stayed in Nodo Island during his exile and wrote many of his works, which are helpful and valuable in developing storytelling content for local cultural development.

The historical and cultural original form (archetype) of the past is important not only for the culture and tourism industry but also for the development of contemporary educational contents. Namhae local government built 'Namhae Exile Literature Museum' to memorize Kim's literature and his life in Nodo Island where his historical and cultural values are contained. In Korea, the museum is the first one to honor the exiled persons and their literary works, relics, and remains. It reflects cultural heritage and their spirit of literature. It will contribute to development of storytelling contents for local cultural industry.

This paper start with three research propositions. First, Man-Jung Kim's literature works and his exile life have enough value to develop global cultural contents. Second, His works have unique characteristics compared to other exile writers. Third, It is valuable to develop storytelling contents systematically from his historical relics and literature works. To answer these questions, we first reviewed the value of his works through previous researches in section 2. Next section, we investigated the other cases of exiled writers such as Jeong-Hui Kim and Yak-Yong Jeong to provide implications on how to develop contemporary storytelling contents. Finally, we propose a framework how to develop a storytelling contents systematically by using three basic elements: 'text + narration + champ'.

The purpose of this study is to make creative plans for developing storytelling contents and promoting local tourism and culture industry using Man-Jung Kim's valuable works. Development plans on storytelling contents were conducted through brainstorming with scholars and experts. Ultimately, this study will contribute to the development of a creative plan for storytelling content, as well as provide research methods on the development of storytelling contents based on local cultural assets.

\section{Value of Man-Jung Kim' Literature Works}

Man-Jung Kim, during his exile, wrote various poetry and novels including "Yunssi-Haengjang", "Sassi-Namjeonggi", the second volume of "Seopo-Manpil" (random Essays), "Seopo-Jip" (random poems and prose), and others. Most of the works show his 
remorse and faithful allegiance to his lord, King Sukjong. One of his numerous works, "Guunmong: The Cloud Dream of the Nine"[1] was not only translated into English as the most outstanding work, but also brought in numerous subsequent studies[2-4]. It's first English translation by James S. Gale was published in 1922[5].

The previous researches on Man-Jung Kim's philosophy and works have the following characteristics[6]. First, the multidisciplinary research on the original text of "Guunmong" as one of the research areas of bibliography is varied because there were no specific literature on its original text. For instance, some researches argue that the original version was written in 'Chinese' while the others in 'Korean'[7-9]. There were also some other translated version of it as foreign language[5][[10][11], which brings different opinion about the original text.

Second, there were diverse theories analyzing the background of the creation of the work, its structure, the writer's consciousness, the psychological variable, and the educational factor among others[12][13]. Thus, in-depth researches on the background and theory of his representative works such as "Guunmong" and "Sassi namjeonggi" will provide not only an understanding of the narrative but also numerous contents that have been used as storytelling on the cultural industry. For example, Zhouyi (The I ching, The Book of Changes) was used for studying the background of "Guunmong" leading to new academic investigations[14][15]. Guunmong is related to the principle of Zhouyi. This is a good example on the expansion of research areas into different perspectives or thinking system, such as orientalism.

Despite numerous academic studies, it is not enough to develop contents or applications using his works[16]. Only, the Namhae local government is interested in developing storytelling contents based on the Kim's achievements, works, and life in exile. The contents created based on these works will greatly contribute to the accumulation of the national cultural assets as well as the development of the local cultural industry and globalization of the Korean literature. We reviewed the successful cases of developing storytelling contents based on the works of three famous exile writers, Jeong-Hui Kim, Yak-Yong Jeong, and Man-Jung Kim, in the next section. The storytelling contents will contribute greatly to the development of local cultural industry and the accumulation of national cultural assets.

\section{Case Study of Storytelling Contents on Exiled Writers}

This paper used Kwang-Wook Kim's theory (2008)[17] for the development of storytelling contents on Man-Jung Kim. This theory changes the concept of storytelling from the "Champ" theory of Pierre Bourdieu to "Text + Narrating + Champ"[18], which covers the total 
A Study on the Development of the Storytelling Contents based on the Exile Life and Literature Works of Man-Jung Kim

environment of the story to ensure narration. Kim's storytelling applies the concept of "story + narration + champ", indicating the comprehensive environment or overall structure that makes no distinction between hardware and software spaces. Therefore, the storytelling may be called the environment that covers the contents converted from the transferred cultural resources and by modern content styles spatiotemporally. This section presents the storytelling contents of three famous exiled Korean writers. It covers museum (hardware) for local tourism and cultural industry as well as the stories of the exiled writers and their literary works (software).

\subsection{Dasan Yak-Yong Jung's Storytelling Contents}

Yak-Yong Jung (1762 1836), pan-name Dasan, was a practical scholar in the late Joseon Dynasty. He had lived in exile for eighteen years since 1801 . He, even in exile, was a historical figure holding unchallenged position in exile literature because he devoted his life to studying Confucian Classics and fostering younger students. His researches in Sauijae, Boeunsanbang, and Dasanchodang were published in complete form of 503 volumes, 182 books, called "Yeoyudang-jip"[18], which has become a basis of modern storytelling contents.

Dasan Museum was opened in Gangjin-gun Jeollanam-do, in 2014. It is located at about 700 meters below Dasanchodang where he lived during his exiled period. It is also used as a local culture and tourism contents. There are plenty of storytelling contents related to Dasan such as sculptures, experience events, interactive media art, and digital arts displayed in the memorial hall and Dasan Exile road[19].

The area around Dasan Heritage Site in Namyangju-si was reorganized and designated as Monument No. 7 by Gyeonggi-do. Yeoyudang, his birthplace, and Silhak Museum, his grave was located here. Silhak in Korean means pragmatism. The museum was opened in 2009 as historical and cultural heritage in Namyangju-si. It has an exhibition room, experience room, and video room relating to Dasan. There are many valuable items to develop storytelling contents in the museum[20].

Dasan's achievements associated with historical and cultural value are extremely global. In Suwon Hwaseong Museum, there are Geojunggi (Korean traditional crane) and Yuhyeonggeo (Korean traditional wagon) designed by Dasan, which are used for fortress construction[21]. However, only few storytelling contents were made about Dasan's achievements. Various ongoing efforts on this are underway.

Dasan Culture Festival is typical storytelling content festival to enhance and inherit Dasan's studies and ideas with the citizens. It has its own ground for his achievements as valuable 
cultural assets. Luckily the archetype of all Dasan's achievements was well preserved. The three local governments - Gangin-gun, Namyangju-si, and Suwon-si - contributed to manage and reorganize his achievements. The cities are the 'champ' of storytelling, where people can see the historical and cultural achievements of Dasan. In particular, the works created during his exile are the most important materials in the development of storytelling contents.

\subsection{Chusa Jeong-Hui Kim's Storytelling Contents}

Jeong-Hui Kim(1786 1856), pan-name Chusa, a great scholar in the late Joseon Dynasty, advocated for Silsagusi movement (find truth in real work). He had lived in exile in Jeju Island for eight years and three months since 1840. In exile, he made Chusache (Kim's original calligraphic style) and left many artworks such as poetries, pictures like Sehando, and letters among others. In 2010, the "Hall of Chusa" was opened in Jeju Island with permanent exhibition halls and experience rooms. The exile area in Daejeong-eup, a small town in Jeju, was designated as Historical Site No. 487, which was the starting point of the development of his storytelling[22].

There are many contents and events related to him such as 'Chusa Culture and Art Festival', 'Ask Chusa the New Way', 'National writing contest to commemorate Chusa', 'Chusa font calligraphic contest', and 'Acrostic poem making with Sehando' in the town of Daejeong-eup. The Hall of Chusa has exhibited and distributed diverse kinds of cultural products for the visitors, including tea sets (Chusa tea sets), water container for an ink stone, eco-bags, bracelets, ceramic tea-kettles with a spout, Sehando tea mats, art lamps, Sehando hanging scrolls, fountain pens, etc.[22].

Jeong-Hui Kim was born in Yesan-si, Chungcheongnam-do. The House of Chusa preserves his relics, remains, and others. In 2008, Yesan-si built 'Chusa Museum' to systematically inherit and exhibit his relics. There are various cultural contents linked with Tomb of Chusa, Chusa Museum, Experience Center of Chusa, etc. It has been a representative local brand because visitors can see and experience his Shishuhua(combination of poetry, calligraphy, and painting), chronicles, and articles left by him[23].

Gwacheon-si, Gyeonggi-do is where Chusa spent his latter two years after living in exile in Buk-cheong, Hamgyong-do. There is a special feature in relation to the development of Chusa's storytelling contents led by the city. The project for Chusa has successfully performed after publishing a research report relating to Chusa in 1996[24]. Particularly, academic studies have been actively based on about 2000 relics donated by Japanese Chikashi Fujitsuka, a researcher 
A Study on the Development of the Storytelling Contents based on the Exile Life and Literature Works of Man-Jung Kim

who studied Chusa. The city also restored Gwajichodang where Chusa had lived and opened 'Chusa Museum' in 2013. The museum store numerous storytelling contents by collaborating with 'Dasan Heritage Site' and 'Silhak Museum', and has systematically managed many cultural assets, including exhibition items, education data, relics, academic researches, etc.

Chusa's storytelling contents have their own hardware mingled with local characteristics focusing on relics in the area. In terms of the concept of storytelling, the environment of 'Champ theory' is well constructed. This led to a variety of storytelling contents such as poetries, pictures, novels and others due to the active publications of writers. Unlike Man-Jung Kim's storytelling, his success via digital media such as drama, documentary, animation, etc. have been regarded as a modern style.

Chusa's storytelling contents are enthusiastically pushed forward without regard to his life, childhood, and exile period. This is its advantage because it found possibility in the field of local culture industry. Hence, the memorial hall and museum will be a complex at the zenith of his storytelling, thereby preserving and inheriting tremendous cultural assets resulting from relics to produce new cultural contents. His storytelling contents are systematically run by combining 'text + narration + champ', so its quality seems to be high. However, because there has been no world-class contents, there would be need to make a new plan by collaborating with readers, storytellers, cultural businesses, and local governments.

\subsection{Seopo Man-Jung Kim's Storytelling Contents}

In Namhae, about 100 ancient sages were lived in exile during the Goryeo Dynasty (Korea Dynasty) to Joseon Dynasty. There are many literary works by them. Namhae have been consistent efforts to develop local cultural contents with conferences, historic and cultural researches. 'Namhae Exile Literature Museum' was opened in 2010 to store and exhibit the achievement of storytelling contents. It houses other facilities such as the experience center, video room, and literature information center. Other contents include Man-Jung Kim Literary Prize, conferences, and writing contests. Namhae is developing the identity of exile culture into the cultural industry[25]. Namhae has a plan to open a theme park providing tour in Nodo island, Man-Jung Kim's historic site, by July 2020. This will not only enhance spatial accessibility as the center of storytelling, but will also become an important cultural tourism resource in the region. These are required to build a foundation of storytelling in a broader sense and to find the identity of exile literature. Exhaustive studies on bibliography and comprehensive literatures are necessary. 
Man-Jung Kim was born in Ganghwado Island and grew up and build his political base in Seoul. Later, his family and descendants lived in Daejeon. He was exiled for about three months in Goseong-gun, Gangwon-do, about a year and two months in Sunchoen-gun, and about three years and a month in Namhae. "Guunmong", written in Sunchoen, and "Sassi-Namjeonggi", written in Namhae, are considered to be his great and significant achievements. Because Sunchoen is located in North Korea, it is impossible to collaborate because of North-South division. Therefore, exile literature and storytelling of Man-Jung Kim in Namhae can establish its own identity. Futhermore, there is a need to collaborate Namhae and Dejeon together for memorial business association to develop Seopo's storytelling contents.

There are some resources about Man-Jung Kim that contribute to tourism industry and local culture. Among them, the most representative are Man-Jung Kim Literary Prize, drama entitled "It's sad to be forgotten", game of the Cloud Dream of the Nine, Madanggeuk (play in open place), and some novels. The development of storytelling content for exiled people should be carried out for research purposes as well as for the development of local and national content industries. Various cultural resources and technology can be used to create new contents which was implemented by characters, backgrounds, and incidents in an original form.

\section{Research Method}

\subsection{A Framework for the Development of Storytelling Contents}

Most of the cultural contents can be defined, consisting of three factors (aspects) such as 'mental, material, and historical aspects' by Ernst Cassirer[26]. The mental aspect represents an original form (Text) of culture. The material aspect and physical features (Narrating) as well as the historical aspects (Champ) imply that interpretation should be integrated to understand the features properly. Here, the most critical point is that the three factors should be permeated with each other under strong correlation, otherwise it only shows fragmentary point[26]. The three components can be applied to adjust the balance between core value and storytelling contents of Man-Jung Kim. In other words, it is essential not only to emphasize a specific factor but also to pursue integration of aspects for successful outcomes of storytelling.

Therefore, storytelling of Man-Jung Kim should include literature value (Text), socio-economic aspects (Narrating), and historic-cultural components (Champ). The champ based storytelling is designed to deduce reasonable results where the factors are complementarily related. Therefore, it is ideal to develop cultural resources and storytelling contents on the entire frame of 'text + 
A Study on the Development of the Storytelling Contents based on the Exile Life and Literature Works of Man-Jung Kim

narration + champ'. The storytelling contents should be designed and managed to include the three aspects of 'literary value, historical and cultural properties, and socioeconomic aspect' for a broader culture industry.

\subsection{Survey Method}

This study suggests a strategy on how to develop contents based on exile culture, and invigorate them on the applicable industry. To develop the strategy, we conducted brainstorming with 12 selected experts in diverse areas, mostly from the field of literature, regional study, history, and public administration. Before the brainstorming, the experts visited "Namhae Exile Literature Museum". Afterwards, each participant answered the pre-designed survey sheet. It contains questions such as "how to improve the values of contents of Man-Jung Kim", "how to develop the contents", "how to activate local cultural industry", and "how to develop local contents industry based on exile culture". The ideas on the survey were shared with all participants. All the ideas and comments were listed and analyzed to develop evolutionary strategies.

\subsection{Brainstorming Results}

The brainstorming with the 12 participants resulted to the following suggestions:

(1) Administrative Supports: cooperation with the local government, excavation of historical culture and linkage development with other culture, strategy for easy accessibility, an increase of historical values

(2) Contents Development: development of cultural products, production of web drama, development of characters of exiled persons, production of web-toon, production of comic books, drama, movie, travel package, development of contents for integrating the experiences

(3) Activities and Events: attraction of foreign travelers, festival for Man-Jung Kim, upgrade of experience program (exile, baking), remind of historical and cultural meanings, promotion of values meanings of the attraction (SNS), contents contest, theme park, application of enjoyable subjects, promotion of the region (photo spot), promotion of contents using SNS, YouTube, etc.

(4) Information Support: information providing on Man-Jung Kim, information of exilic history, enhanced accessibility to exiled person's life 
The cultural aspects were not mentioned, instead, there was almost an opinion that historical, cultural, and socioeconomic values should be improved. There was an opinion that economic values should be mitigated. Currently, no goods of cultural products related to Man-Jung Kim existed in Namhae. Thus, they proposed to develop characters and application goods, products related to daily supplies, and souvenir for travelers. It can be realized by collaborating local culture artists. They can co-work based on the coexistence and local economic development. In addition, a scope of 'champ' is to develop internet platform for distribution and deliver the contents on it.

\section{Champ Theory and Storytelling Contents for Man-Jung Kim}

Folk culture of humankind is a vital substance. It needs to identify how culture archetype is presented through a flow of semantic and cultural contexts[27]. Such logics have been changed and repeated to approach convergence and complex compositions compared to the existing components when developing the contents of storytelling. It implies a meaning of emphasis regarding originality or identity including traditional factors of culture. The development plan on storytelling of Seopo should address its lack of diversity of contents compared to the cases of Yak-Yong Jeong or Jeong-Hui Kim. It suggests a necessity of inspecting the current situation by reviewing Kwang-Wook Kim's conception[17]. Table 1 indicates the storytelling contents currently under development utilizing the three core factors using Cassirer's cultural objects and 'champ' theory. It shows how to establish together both the core factors and champ theory to develope his exile life contents.

[Table 1] Classification of Man-Jung Kim's Cultural Contents

\begin{tabular}{|c|c|c|c|}
\hline Items & \multicolumn{3}{|c|}{ Classification } \\
\hline $\begin{array}{c}\text { Kwang-Wook Kim's } \\
\text { Theory }\end{array}$ & Text & Narrating & Champ \\
\hline $\begin{array}{c}\text { Ernst Cassirer' } \\
\text { Theory }\end{array}$ & Mental aspects & Material aspects & Historical aspects \\
\hline \multirow{3}{*}{$\begin{array}{c}\text { Man-Jung Kim's } \\
\text { Exile Contents }\end{array}$} & Literature of exile & $\begin{array}{c}\text { Acculturation of current literature, } \\
\text { Man-Jung Kim Literacy Prize }\end{array}$ & $\begin{array}{c}\text { Namhae Exile Literature } \\
\text { Museum }\end{array}$ \\
\cline { 2 - 4 } & $\begin{array}{c}\text { Original form of } \\
\text { culture }\end{array}$ & $\begin{array}{c}\text { Seopo Cultural Festival, } \\
\text { Memorial Ceremony }\end{array}$ & $\begin{array}{c}\text { Seopo Literature Park } \\
\text { Nodo Island }\end{array}$ \\
\cline { 2 - 4 } & The Cloud Dream of the Nine & Guunmong-gil \\
\hline $\begin{array}{c}\text { Man-Jung Kim's } \\
\text { Core Value }\end{array}$ & $\begin{array}{c}\text { Literary value } \\
\text { (Archetype) }\end{array}$ & Socio-economic elements & Historical cultural resources \\
\hline
\end{tabular}


A Study on the Development of the Storytelling Contents based on the Exile Life and Literature Works of Man-Jung Kim

Two cases of modern acculturation work using digital technology existed in the development cases. It is belong to Narrating. First, KBS drama 'It's sad to be forgotten'[28] based on the novel of writer Tak-Hwan Kim was broadcasted in 2005. It used the concept of the purpose novel of "Sassi-Namjeonggi" to describe the antagonistic relationship between Queen Inhyeon and Royal court lady Heebin Jang as Metafiction[29]. Second, The game of 'The Cloud Dream of the Nine' developed by Neo Elis's game company is recreated as a form of love adventure game on the subject of love stories of girls[30]. It is an important milestone in developing storytelling contents of Seopo in the future. In a macroscopic view, this is a case to develop competitive contents by acculturation of original form of culture and convergence of works.

Until today, the Seopo's storytelling is insufficient and unsystematic compared to Dasan's and Chusa's. There were lack of contents because they are focused on hardware of sightseeing products. The recreation of 'story' works has been developed through the writers of Man-Jung Kim Literacy Prize contest. The level of development of contents integrated with digital technology is still in an early stage.

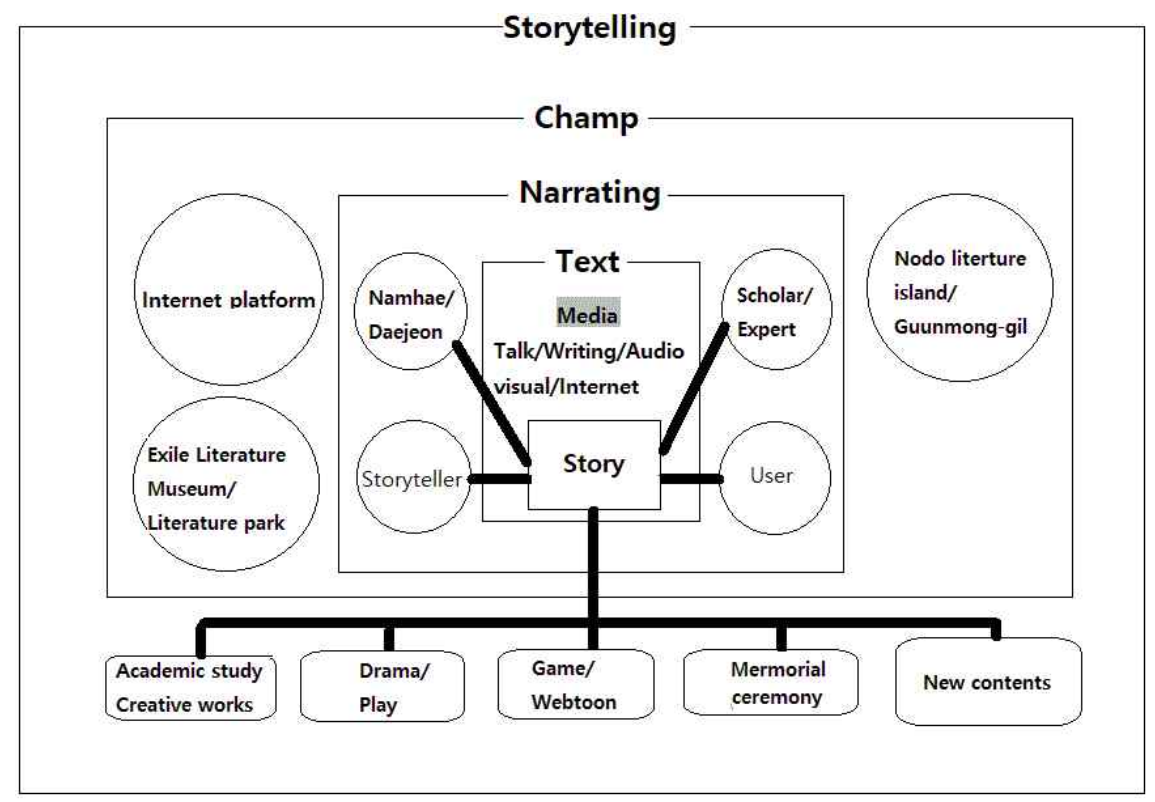

[Fig. 1] A Scheme of Man-Jung Kim's Storytelling

[Fig. 1] describes the integrating cases of storytelling of Man-Jung Kim. First, 'Text' is to realize the storytelling integrally, a variety of archetype contents (original and typical type) should be presented by combining each story with the media operated by cultural technology. The contents of story as indicated in [Fig. 1] show a lack of contents regarding exiled persons 
compared to other types of contents except for bibliography, arts, and background of writers. Second, 'Narration' should be guaranteed by communication environment regardless of time and place. Storytellers, readers, experts, scholars, and local government should upgrade storytelling work by sharing ideas and cooperation. Third, 'Champ', place for demonstration, contains not only hardware like museum but also internet platform that is useful to make and deliver the contents efficiently. The platform should be built by high information and communication technology and cultural convergence technology, and should have reproduction and experience space.

\section{Conclusion and Implications}

'Namhae Exile Literature Museum' was built to enhance cultural values using Kim's literatures written during his exile. The narratives in Man-Jung Kim's literatures can possibly succeed in the development of global storytelling contents. For the success of the project, collaborative efforts among local governments, scholars, cultural businesses, storytellers, readers, and others are necessary.

This paper suggests how to develop storytelling contents about Man-Jung Kim. The related components within the frame 'Text + Narration + Champ' means that integrated viewpoints are required to produce new storytelling and the corresponding contents. A lack of diversity and depth regarding the core values in 'literary, socio-economic, and historical/cultural viewpoints' and contents aspects were reflected in the storytelling contents of Man-Jung Kim, who had reached a great scholar position like as Jeong-Hui Kim and Yak-Yong Jeong. This paper suggests a new development scheme of storytelling contents of Man-Jung Kim and highlight improvement points for developing storytelling contents through investigating a similar cases of exiled person.

The brainstorming with 12 experts gave us various ideas to develop the strategic plans and combined concepts of storytelling as well as pathway towards the development of new storytelling contents on Man-Jung Kim. First, in storytelling of Man-Jung Kim, 'Text' includes not only the contents of original literatures or works but also the modern types of media. It is recreated by storytellers, writers, producers, and public contests. Second, 'Narration' has a different meaning with one-way flow of cultural product in the order of writer and reader. It means an interactive environment based on strong scale out and up, which is the strength of high technology such as IoT and AI technology. Third, 'Champ' is a systematic operation system as a basis of cluster configuration for local culture business, for instance, museum, 
A Study on the Development of the Storytelling Contents based on the Exile Life and Literature Works of Man-Jung Kim

memorial hall, and literary hall. Especially, it includes an internet platform for distribution and implementation of contents. Consequently, a strategy to develop storytelling of Man-Jung Kim should be implemented by integrating the three concepts for a successful outcome.

The critical success factor is the person who participates in storytelling work at the stage of 'Narrating'. They determine whether the storytelling of the exiled persons is effective. Moreover they suggest how to improve the contents because they are arbiter of contents activation as well as the reader(consumer and citizen). Moreover, today's citizens(readers and consumers) are playing an important role in producing interactive storytelling contents as a host or prosumer. Concludingly, the cooperation and collaboration among producer and consumer is the key to success in developing storytelling contents.

\section{Acknowledgement}

This paper was developed by the support of BK21 Plus 'Cultural Convergence and Business Model Development Team' and Dept. of Cultural Convergence, Graduate School, Gyeongsang National University.

\section{References}

[1] Man-Jung Kim, Kuunmong(九雲夢), (1689)

[2] Kyu-Bok Chung, Guunmong Data Aggregation 1, 2, 3, Bogosa, (2010)

[3] Sung-Gyung Sul, A Chronical Approach to Kuunmong, Saemunsa, (2007)

[4] Kyu-Bok Chung, Some Comments on Ku-un-mong, Classic Interpretation, (2006), No.1, pp.129-148.

[5] Man-Choong Kim, The Cloud Dream of the Nine: A Story of the Times of the Tangs of China about 840 A.D., (Translated by James S. Gale), The Westminster Press, (1922)

[6] Byung-Gook Kim, Seopo Kim Man Jung, His Life and Work, Seoul National University, (2001)

[7] Kil-Soo Chung, A Research on Texts of Koo-woon-mong, The Research of Old Korean Novel, (2007), No.23, pp.5-34. UCI : G704-000481.2007..23.002

[8] Kil-Soo Chung, Review on Guunmong Text Studies, Institute of Humanities, Chosun university, (2018), No.55, pp.163-190.

[9] Daniel Bouchez, Articles : On the Original Language of Kuun mong (九雲夢), Journal of Korean Studies, (1992), Vol.18, No.3, pp.3031-3061. UCI : I410-ECN-0102-2008-910-000440070 
[10] Man-Jung Kim, The Nine Cloud Dream, (Translated by Heinz Insu Fenkl), Penguin Classics, (2019)

[11] Man-Jung Kim, Kuunmong: The Cloud Dream of the Nine, (Edited by Susanna Fessler), Kurodahan Press, (2003)

[12] Mu-Jo Kim, The Background of Construction of Kim Manjoong's Fiction, Journal of Koreanology, (2008), Vol..2, pp.1-30. DOI : 10.22861/tiks.2008..2.1

[13] Daniel Bouchez, Special Contribution: On the Ku unmong, THE DONG BANG HAK CHI, (2006), No.136, pp.387-409. UCI : G704-001255.2006..136.005

[14] Young-Hee Bae, Myths, Zhoyi and Guunmong, Minsogwon, (2006)

[15] Jae-Hong Shin, The Relationship Between Guunmong and Bok-gwae, The Classic Literature and Education, (2018), No.38, pp.139-173. DOI : 10.17319/cle.2018..38.139

[16] Su-Gon Yi, The Theoretical Considerations of 'Storytelling', The Treatise on The Plastic Media, (2018), Vol.21, No.1, pp.120-127.

[17] Kwang-Wook Kim, The Research on the Conception of Storytelling, Journal of Korean National Language and Literature, (2008), No.41, pp.249-279. UCI : G704-001823.2008..41.005

[18] Yak-Yong Jung, Yeoyudang-jip, Manuscript, (1883)

[19] http://www.gangiin.or.kr/culture/dasan.asp, Jan 06 (2020)

[20] https://silhak.ggcf.kr, Jan 06 (2020)

[21] https://www.suwon.go.kr/index.do, Apr 20 (2020)

[22] https://www.jeju.go.kr/chusa, Jan 06 (2020)

[23] http://www.yesan.go.kr/tour, Apr 20 (2020)

[24] https://www.gccity.go.kr/chusamuseum/main.do, Apr 20 (2020)

[25] http://namhae.go.kr, Jan 06 (2020)

[26] Wan-Kyu Park, (trans), Ernst Cassirer, The Logic of Cultural Science, Gil, (2009), pp.176-177.

[27] Ki-Dae Lee, Geun-Hye Kim, The World of Cultural Prototypes and Contents, Prunsasang, (2016)

[28] Tak-Hwan Kim, It is Sad to be Forgotten, Dongbang Media, (2002)

[29] Hui-Bok Song, Manjoong Kim, Reading in the Literature of Our Times, Exile Research 1, Namhae Exile Literature Museum, (2012), pp.20-24.

[30] http://dream9.neoalice.co.kr, Jan 06 (2020) 